Volume $50 \cdot$ Number $4 \cdot 2013$

\title{
REFLECTIONS ON "BIOENGINEERING EVALUATION AND FIELD TEST OF THE STAND-ALONE THERAPEUTIC AID"
}

\section{RONALD J. TRIOLO, PHD}

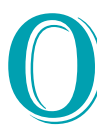

ur thinking and approach to research and assistive technologies have evolved significantly since the publication 50 years ago of "Bioengineering evaluation and field test of the Stand-Alone Therapeutic Aid." The most striking change is in the value placed on basic discovery and knowledge generation, in addition to device development and verification testing. This evolution from a "Consumer Reports" mentality, where assistive technologies are field tested, to prospective, controlled trials of fundamental concepts and mechanisms as well as therapeutic and technical interactions is a paradigm shift in rehabilitation. We put a much higher premium on investigatorinitiated (or "Department of Veterans Affairs [VA]-initiated") research today, in contrast to "VA-evaluated" studies. This sea change in the role of the VA as a ready source for test subjects to a research-driven organization capable of generating new theories, planning, and executing sound methods for testing hypotheses and conducting world-class science and interpreting the results in the context of both clinical practice and their effects on new fundamental understanding of underlying physiological, functional, and societal implications is profound. JRRD has grown up and successfully transitioned from a journal of product development, anecdote, and speculation to one dedicated to evidence-based practice and data-driven conclusions.

One interesting aspect of the last half century evident from this article is the maturation and development of a systematic approach to spinal cord injury classification and treatment. Written before international standards for neurological classification or identification of the continuum of measurement domains that discriminate between physiology, capacity, performance, and societal impact, the article, if carefully read, should engender gratitude in those working in spinal cord injury research in particular and rehabilitation research in general. The time, energy, and detail expended to describe the clinical presentations of the study cohort by the authors is astounding, especially in light of the relatively easy methods now at our disposal because of the hard work of numerous people over the intervening years to develop standards and classification systems that allow us to speak the same language without having to reinvent it. Our research subjects and the general consumers of rehabilitation services and technologies are also probably far more accepting of novel approaches and sensitive to the capabilities provided by revolutions in computing power, material science, wireless communications, and control. It's difficult to image finding volunteers who would be willing to use a device such as the stand-alone therapeutic aid today, even in a short-term trial like the one described in the article.

One aspect that hasn't changed is the emphasis on multidisciplinary and multicenter trials. The report is truly impressive in its emphasis on collaborative work and inclusion of contributions from clinical sites around the country. This kind of research is still extremely difficult to organize and do, perhaps even more so today than at the time of publication. But its value has only increased in recent years as the burden of proof for generalizability and effectiveness of our interventions increases. Even so, JRRD has become much less VA centric than is evident in this contribution, which pooled data from five VA hospitals. The broader net currently cast by the journal only serves the greater clinical needs of veterans with disabilities today.

It's hard to imagine JRRD publishing an article this long or this detailed of an analysis of a single piece of existing equipment today. It's an extremely comprehensive and thorough analysis from mechanics through subjective perceptions and user feedback, including detailed case histories and user feedback that border on anthropological or ethnographic study. What is lacking in statistical analysis, hypothesis-driven methods, and controls is certainly complemented by its scope. Maybe we can learn to recapture some of this dedication to the big picture to flesh out our new-found reductionist tendencies. 